\title{
Real-world treatment and patient-specific characteristics of actinic keratosis in the USA
}

\section{Jes B. Hansen ${ }^{1}$, Mads D. Faurby ${ }^{1}$, Meg Corliss², Steven R. Feldman ${ }^{3}$}

${ }^{1}$ LEO Pharma A/S, Ballerup, Denmark; ${ }^{2}$ LEO Pharma Inc, NJ, USA; ${ }^{3}$ Department of Dermatology, Wake Forest University School of Medicine, NC, USA

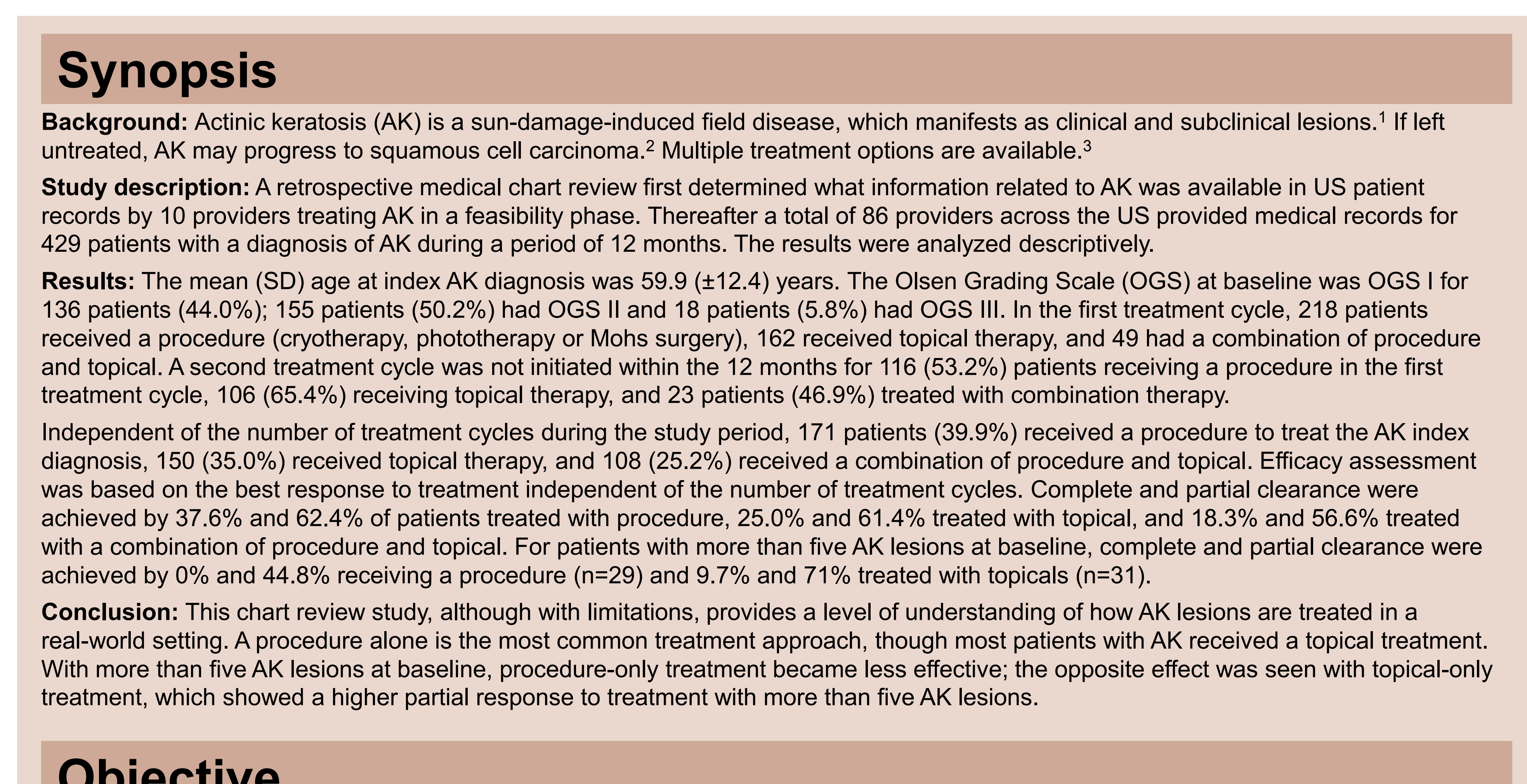

Objective

To describe and understand real-world treatment patterns, and patient-specific characteristics of actinic keratosis (AK) in the USA.

\section{Methods}

Phase 1. Feasibility assessment

The study was pilot tested with 10 clinics

Each provider abstracted six medical records and participated in interviews to assess the functionally
records.

Phase 2. Medical record review

- This was a retrospective medical record review of information on patients with a diagnosis of AK The data were fully anonymized, no personal or identifiable information was collected and there was no patient contact or prospective follow-up.

rovider inclusion criteria

Located in the USA

Dermatologist or nurse practitioner/physician assistant specializing in dermatology with 3-35

years' practice experience

Treated at least 40 patients with AK in the last year

Main decision maker regarding treatment of $A K$

- Detalled information provided in the medical record regarding AK.

atient inclusion criteria

Confirmed diagnosis of AK

- Treatment inlated between January 1, 2012 and September 30, 2014 - First diagnosis treated during this period was considered the 'index diagnosis'

- The AK index diagnosis must have met one of the following definitions on the diagnosis date: AK was new to the anatomical region

AK was new in the patien

New treatment cycle

$\geq 18$ years of age at index diagnosis

Received AK-related care from the same provider or treatment center for at least 12 months

following the index diagnosis dalt.

Study measures

Physician characteristics

Geographic practice region, number of years in practice, current case load of patients with AK.

Demographic characteristics

Gender, age, history of malignancies (prior malignancies versus none).

Clinical characteristics

Anatomical location, number of clinically viable AK lesions, type of lesions, grade of most

representative lesion in region, size of treated area (small, $<25 \mathrm{~cm}^{2}$ versus large, $\geq 25 \mathrm{~cm}^{2}$.

Treatment patterns

Receipt of procedure versus topical treatment (with or without procedure), type and number of specific treatments received, treatment response: complete clearance (AKCLEAR 100), partia

\section{Results}

Baseline characteristics

In total, 86 providers provided medical records for 429 patients.

Provider characteristics are presented in Table 1 and patient baseline characteristics are presented in Table 2 .

Table 1. Provider characteristics

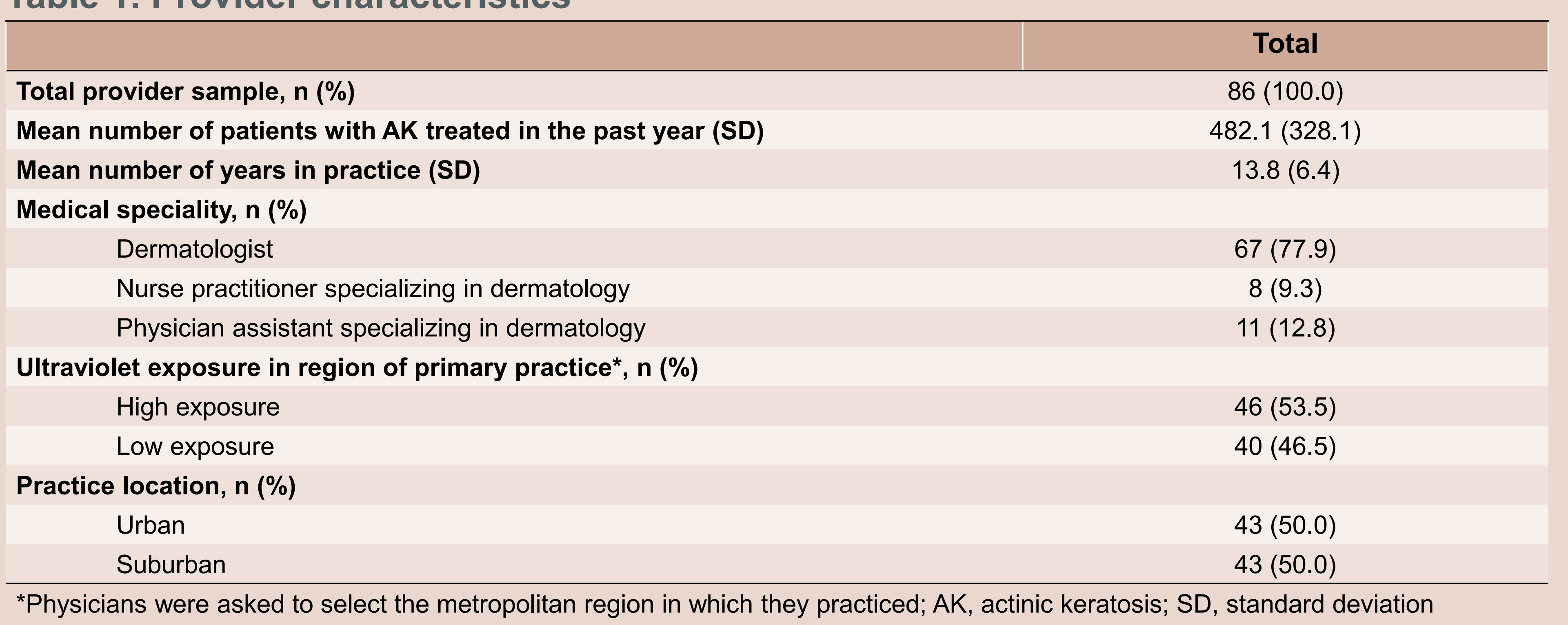

Table 2. Patient baseline characteristics

\begin{tabular}{|c|c|c|c|}
\hline & $\begin{array}{l}\text { Procedure } \\
(\mathrm{n}=171)\end{array}$ & $\begin{array}{l}\text { Topical } \\
(\mathrm{n}=150)\end{array}$ & $\begin{array}{c}\text { Combination } \\
(n=108)\end{array}$ \\
\hline \multicolumn{4}{|l|}{ Sex, n (\%) } \\
\hline Male & 108 (63.2) & $101(67.3)$ & $79(73.2)$ \\
\hline Female & $63(36.8)$ & $49(32.7)$ & $29(26.9)$ \\
\hline Mean age at index diagnosis, $\mathbf{n}$ (SD) & $60.3(12.1)$ & $58.3(13.0)$ & $61.5(11.9)$ \\
\hline \multicolumn{4}{|l|}{ Fitzpatrick classification of skin type at index date, $n(\%)$} \\
\hline I- Always burns, never tans (pale white skin) & $43(25.1)$ & $31(20.7)$ & $20(18.5)$ \\
\hline II - Always burns easily, tans minimally (white skin) & $100(58.5)$ & $78(52.0)$ & $71(65.7)$ \\
\hline $\begin{array}{l}\text { III- Burns moderately, tans uniformly } \\
\text { (light brown skin) }\end{array}$ & $18(10.5)$ & $27(18.0)$ & $15(13.9)$ \\
\hline $\begin{array}{l}\text { IV - Burns minimally, always tans well } \\
\text { (moderate brown skin) }\end{array}$ & $8(4.7)$ & $9(6.0)$ & $2(1.9)$ \\
\hline V - Rarely burns, tans profusely (dark brown skin) & $1(0.6)$ & $2(1.3)$ & 0 (0) \\
\hline Undetermined/don't know & $1(0.6)$ & $3(2.0)$ & $0(0)$ \\
\hline History of malignancies prior to the index $\mathrm{AK}, \mathrm{n}(\%)$ & $59(34.5)$ & $51(34.0)$ & $41(38.0)$ \\
\hline Mean number of baseline lesions (SD) & $6.1(7.5)$ & $6.3(7.8)$ & $7.5(8.6)$ \\
\hline \multicolumn{4}{|l|}{ Field size, $\mathrm{n}(\%)$} \\
\hline Small $\left(<25 \mathrm{~cm}^{2}\right)$ & $122(84.7)$ & $86(65.7)$ & $55(77.5)$ \\
\hline Large $\left(\geq 25 \mathrm{~cm}^{2}\right)$ & $20(13.9)$ & $32(24.4)$ & $16(22.5)$ \\
\hline Unknown & $2(1.4)$ & $13(9.9)$ & 0 (0) \\
\hline \multicolumn{4}{|l|}{ AK thickness (OGS), $n(\%)$} \\
\hline Grade I - mild & $63(43.8)$ & $53(40.5)$ & $20(28.2)$ \\
\hline Grade II - moderate & $53(36.8)$ & $56(42.8)$ & $46(64.8)$ \\
\hline Grade III - Severe & $7(4.9)$ & $7(5.3)$ & $4(5.6)$ \\
\hline OGS was not recorded & $21(14.6)$ & $15(11.5)$ & $1(1.4)$ \\
\hline
\end{tabular}

Treatment pattern

The number of patients that received a procedure to treat the index diagnosis was $171(39.9 \%)$ while $150(35.0 \%)$ patents received topical treatment, and $108(25.2 \%)$ received a combination

Patients receiving each trealment type, based on if they had 1-5 baseline lesions or

(1. Treatment received by number of baseline lesions

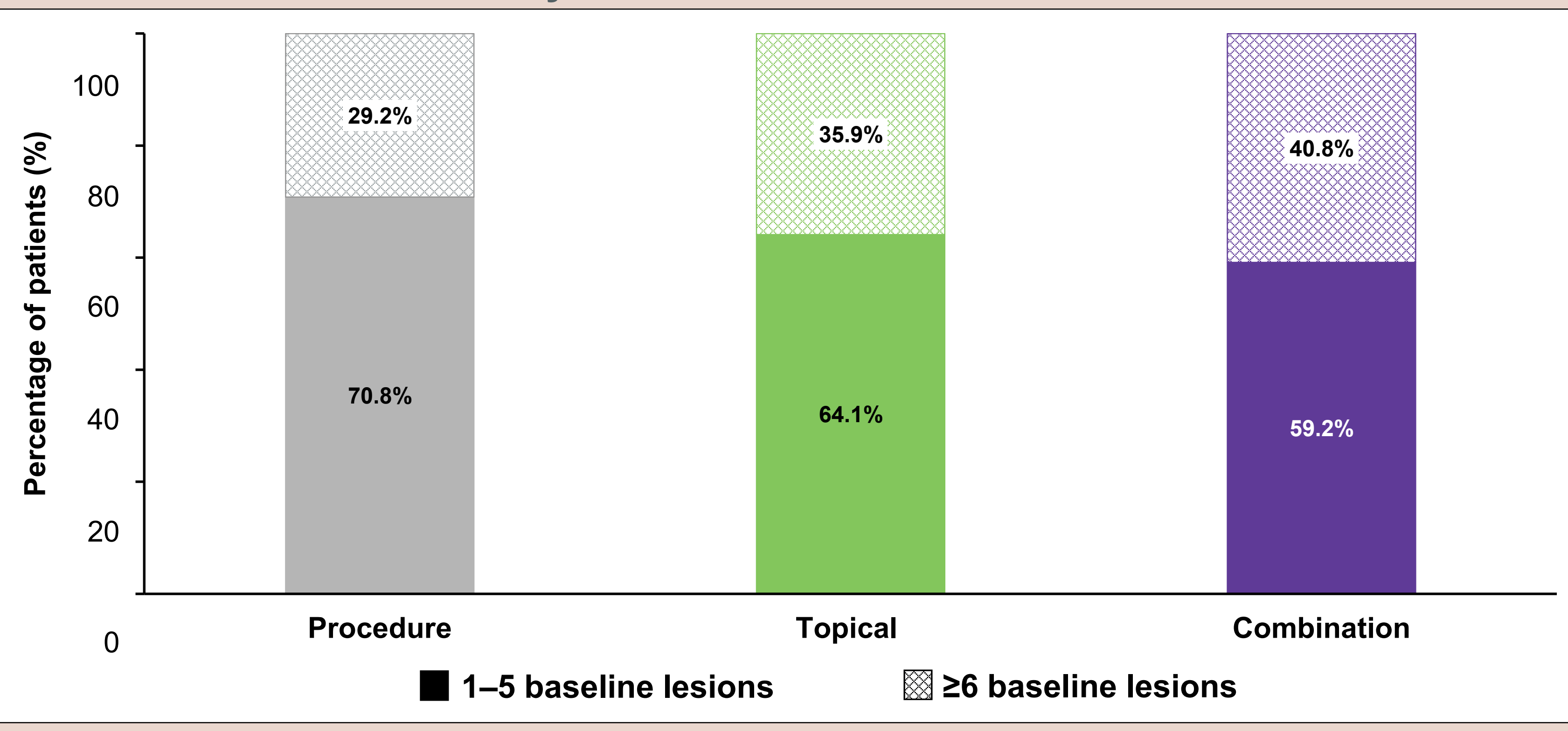

The treatment cycles for the index diagnosis are shown in Figure 2. Figure 2. Treatment cycles per index lesion

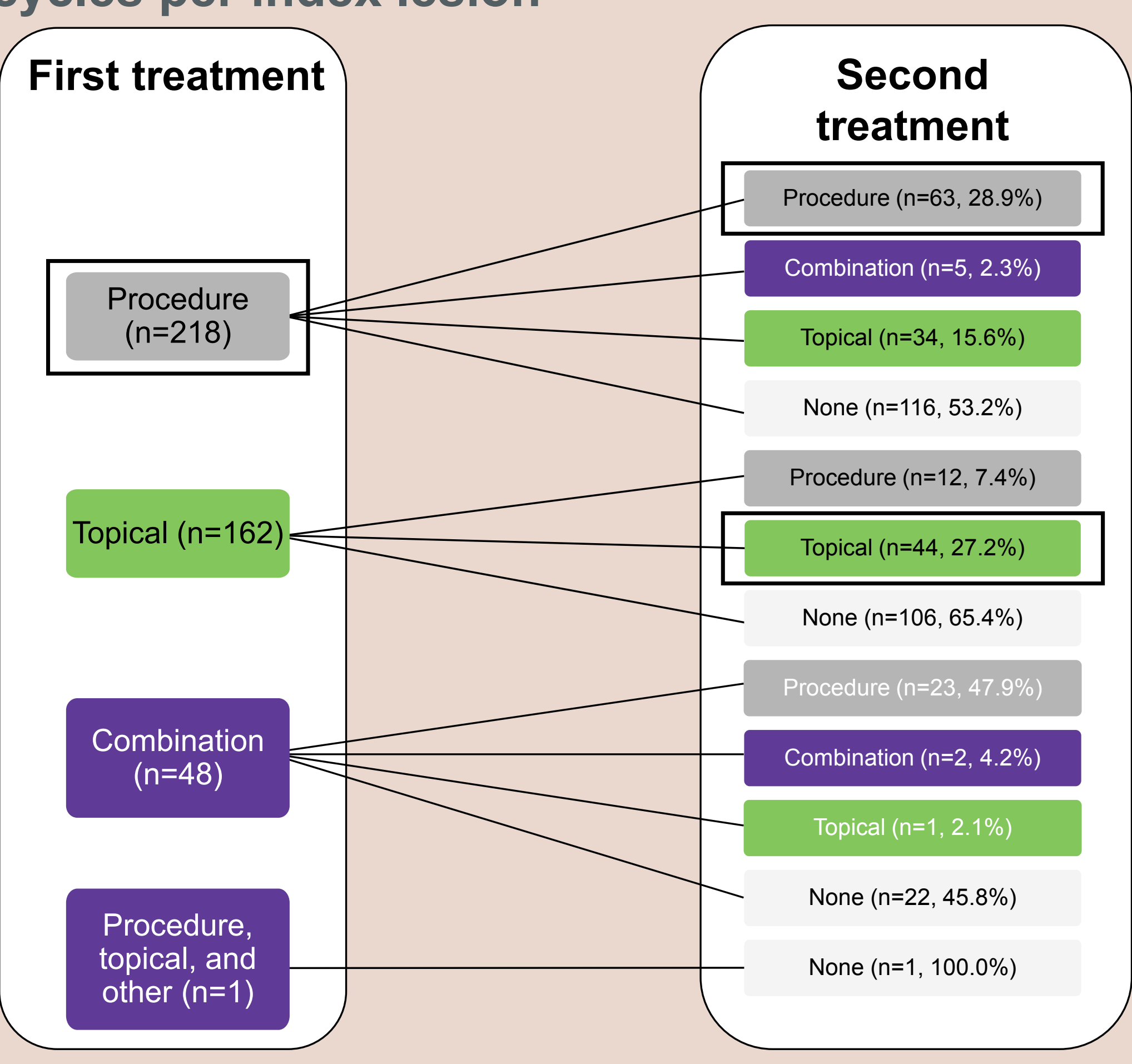

Efficacy

The response to treatment was known for 249 of 429 patients included in the medical chart

review.

Thirty-eight (37.6\%) patients receiving procedural treatment achieved AKCLEAR 100 and 63 (62.4\%) achieved AKCLEAR 75. Twenty-lwo (25.0\%) and 54 (61.4\%) patients receiving topical treatment achieved AKCLEAR 100 and AKCLEAR 75, respectively. Eleven $(18.3 \%)$ respectively. Percent clearance by treatment group is shown in Figure 3

No patients with $>5$ baseline AK lesions $(n=29)$ receiving a procedure achieved AKCLEAR 100 . by number of baseline lesions and by treatment group is shown in Figure 4 .

As number of baseline lesions increased, procedure treatment became less effective (Figure 5A); the opposite trend was seen with topical treatment (Figure 5B). A similar result to
Figure 3. Percentage of patients achieving different levels of clearance per treatment

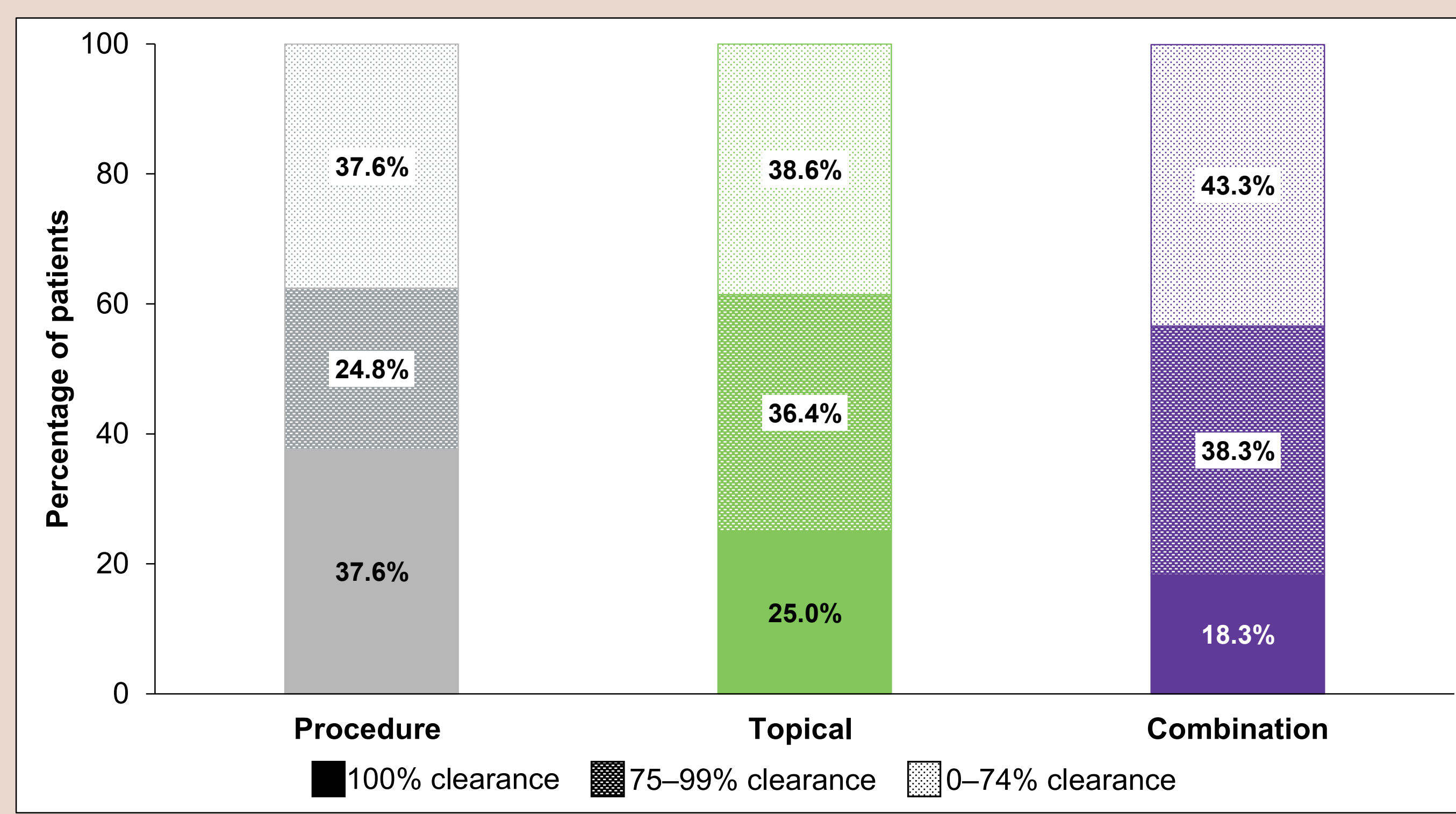

Figure 4. Percentage of patients achieving different levels of clearance per treatment group and by number of baseline lesions

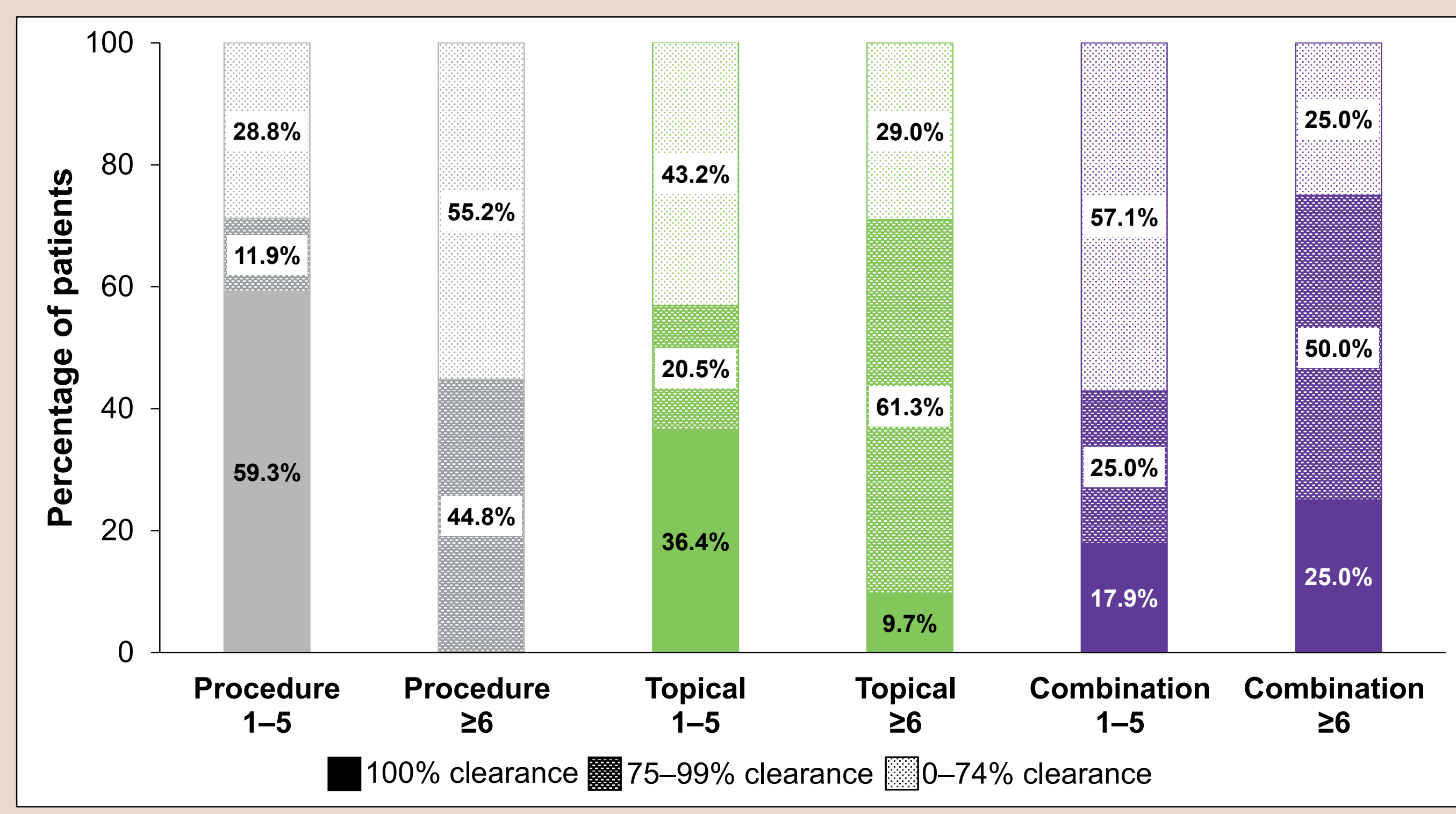

Figure 5. Percent reduction in number of baseline lesions by treatment group: (A) procedure, (B) topical, and (C) combination

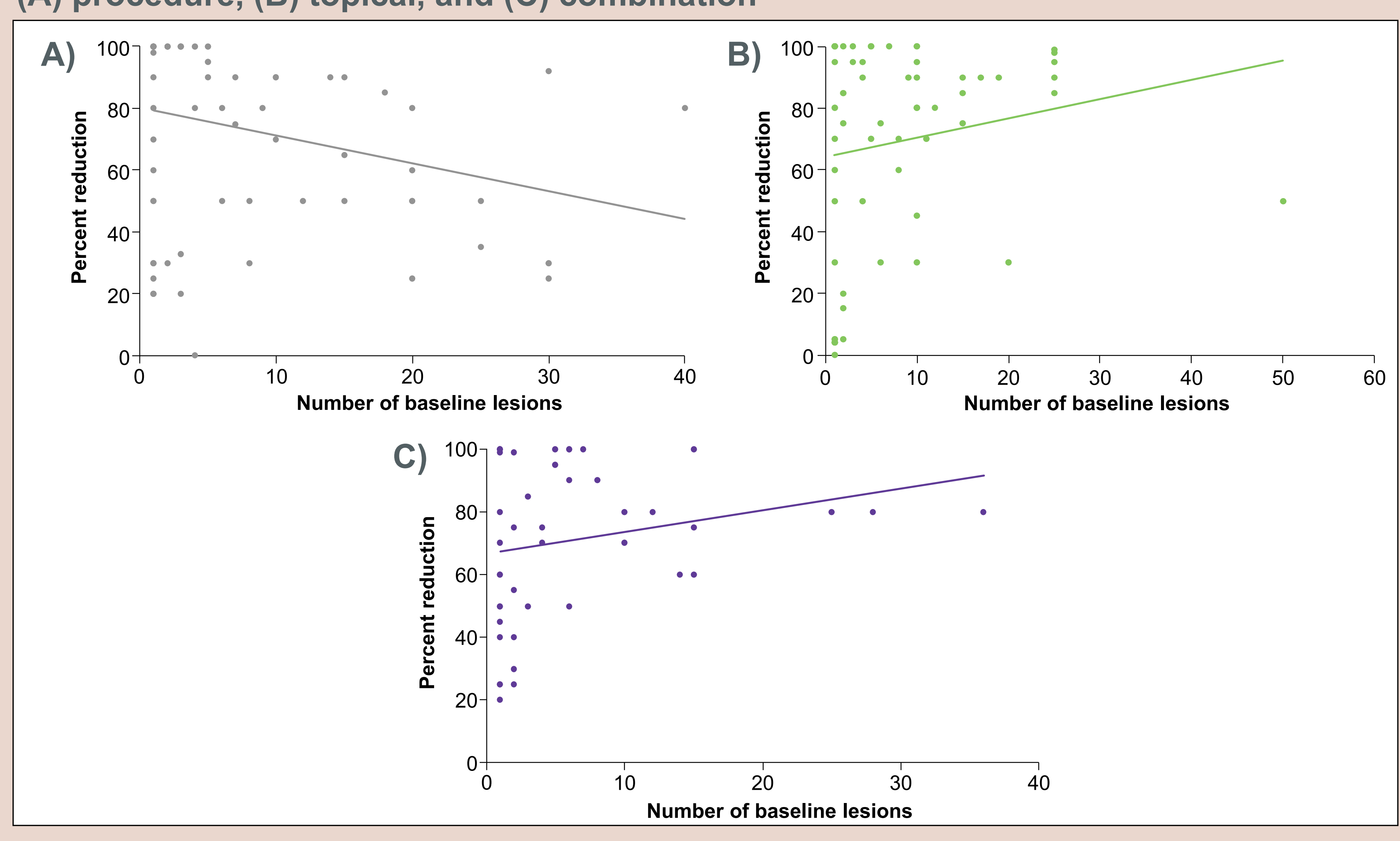

Safety

ARs were more common in the topical group, with $32.0 \%$ of patients reporting $\geq 1 \mathrm{AR}$. In the procedural treatment group, $9.4 \%$ of patients reported $\geq 1 \mathrm{AR}$ and in the combination group, $23.2 \%$ reported $\geq 1$ AR.

The three most common ARs by treatment group are presented in Table 3. Table 3. Most commonly reported ARs by treatment group

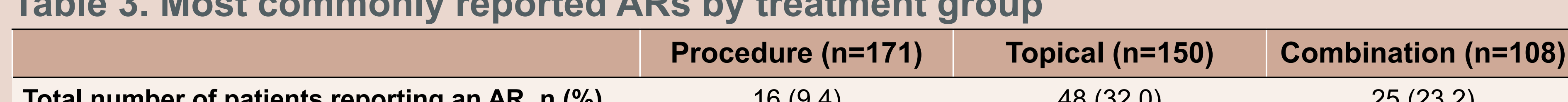
Total number of ARs reported Three most
treatment

\begin{tabular}{|c|c|c|c|}
\hline Pain & $10(41.7)$ & 0 & $4(7.0)$ \\
\hline Bilstering & $7(29.2)$ & 0 & $2(4.0)$ \\
\hline Erythema & $1(4.2)$ & $40(48.8)$ & $20(36.0$ \\
\hline Headache & $4(16.7)$ & $0(0)$ & 0 \\
\hline Prurtitus & $1(4.2)$ & & \\
\hline Edema & 0 & $12(14.6)$ & $2(4.0)$ \\
\hline Dermatitis & 0 & $6(7.3)$ & $9(16.0)$ \\
\hline
\end{tabular}

\section{Conclusions}

U

a topical treatment

Wh more than five AK lesions at baseline, procedure-only treatment became less effective; the (to Acknowledgements and disclosures

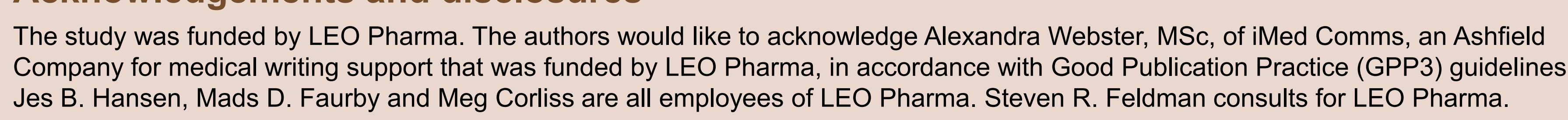

\section{References}

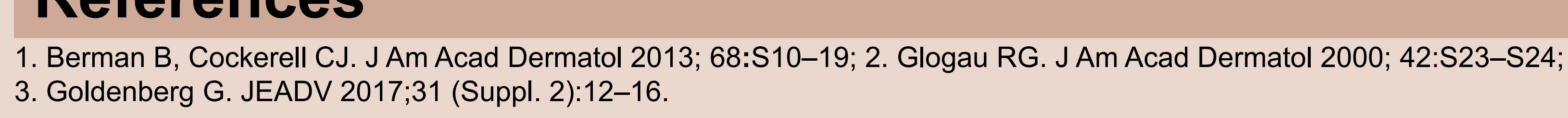

